\title{
Fintech Penetration, Financial Literacy, and Financial Decision-Making: Empirical Analysis Based on Tar
}

\author{
Yi Li, ${ }^{1}$ Zhengwang Li $\mathbb{D}^{2,3}$ Fan Su, ${ }^{1}$ Qiteng Wang, ${ }^{1}$ and Qian Wang ${ }^{4}$ \\ ${ }^{1}$ School of Finance, Hubei University of Economics, Wuhan, Hubei 430205, China \\ ${ }^{2}$ School of Finance, Zhongnan University of Economics and Law, Wuhan, Hubei 430073, China \\ ${ }^{3}$ Hubei Financial Development and Financial Security Research Center, Wuhan, Hubei 430205, China \\ ${ }^{4}$ School of Social Science and Public Policy, King's College London, London SE1 8WA, UK \\ Correspondence should be addressed to Zhengwang Li; 752839498@qq.com
}

Received 20 October 2020; Revised 19 November 2020; Accepted 26 November 2020; Published 24 December 2020

Academic Editor: Wei Zhang

Copyright (c) 2020 Yi Li et al. This is an open access article distributed under the Creative Commons Attribution License, which permits unrestricted use, distribution, and reproduction in any medium, provided the original work is properly cited.

\begin{abstract}
The level of financial literacy of rural residents will affect their financial decisions and the financial well-being behind the decisions. This paper uses mediating effect and moderating effect to test the influence path of rural residents' subjective and objective financial literacy on their financial decision-making with survey data from Henan and Anhui provinces in China. The results show that subjective and objective financial literacy have positive effects on financial market participation. Subjective and objective financial literacy have negative direct effects on insurance market participation. Subjective financial literacy plays an incomplete mediating effect in the impact of objective financial literacy on financial market and insurance market participation. Objective financial literacy is adjusted by subjective financial literacy on financial market participation and insurance market participation. At the same time, we introduce financial technology penetration as a threshold variable in the model and find that the financial literacy has stronger impact on financial decision-making if the financial technology penetration is above the threshold.
\end{abstract}

\section{Introduction}

The family is the basic unit of society and the microfoundation of economic operation. As China's economy continues to maintain a momentum of growth and residents' income increases substantially, various financial investment products have gradually become important carriers of the wealth of Chinese residents. Under such realistic conditions, household financial literacy will have a significant impact on household financial investment decisions and wealth composition. Higher financial literacy helps family investors to achieve the best match between risk and return, thereby increasing income at the average risk level and reducing idle resources.

The academia has not yet unified the definition of financial literacy concepts. At present, they define concepts in the following ways: first, early scholars equated it with financial knowledge. For example, Lusardi and Mitchell examined the situation of consumers' mastery of basic financial knowledge. Second, financial literacy is a comprehensive concept, including financial knowledge and people's ability to process various economic information and make wise decisions on many financial events, such as using financial capabilities to define people's ability to deal with various problems in financial activities [1]. Third, financial literacy includes not only financial knowledge, behavior, and attitude but also personal financial experience, as proposed by Moore [2]. Some scholars combine behavioral finance to interpret and further emphasize the importance of financial education. The OECD defined financial literacy as "awareness, knowledge, skills, attitudes, and behaviors related to financial affairs, which are used in financial decisionmaking to improve personal financial well-being" in the 2015 survey report [3]. In general, this article divides financial literacy into three dimensions: financial knowledge, financial skills, and financial attitude. Financial knowledge and skills belong to objective financial literacy, while financial attitude belongs to subjective financial literacy. 
Xiao et al. proposed that "financial literacy can be divided into subjective financial literacy and objective financial literacy." The measurement of objective financial literacy in the existing literature is mainly based on financial knowledge. The higher the degree of financial knowledge, the more beneficial to investors or consumers make reasonable financial decisions [4]. Dohmen et al. found that abundant financial knowledge can help families understand the profits and risks of financial markets and financial products which can reduce the preparation costs of families in the early stages of making financial decisions [5]. Roooij et al. researched on Dutch DHS data and found that the majority of respondents only understand basic financial knowledge, such as funds, which have higher returns than savings, and any investment is risky, but do not know about slightly professional financial knowledge, such as calculation of the interest rates of savings and investment returns and the relationship between bond prices and interest rates [6].

Although there are few researches on assessing financial behavior based on people's subjective literacy, an upsurge surrounding subjective financial literacy is taking shape. More and more scholars have discovered that although objective financial literacy can affect personal financial decisions, the subjective willingness of individuals in making decisions also restricts decision-making behavior. Robb pointed out that both subjective and objective financial literacy will affect financial behavior, and subjective financial literacy has a greater impact [7]. Zhang and Xiong found that subjective financial literacy has a direct effect on residents' financial decision-making and affects the role of objective financial literacy in financial decision-making [8].

At the same time, what we need to see is that with the gradual penetration of new digital finance such as financial technology into the rural financial market, more rural residents are participating in the financial market and increasingly complex financial products and services have continuously improved the financial literacy requirements of rural residents. The phenomenon of rational financial decision-making has gradually emerged. Under different financial technology popularization, the impact of rural residents' financial literacy on financial decision-making may change significantly, but the existing literature lacks a combined analysis of financial technology, financial literacy, and financial decision-making. In view of this, this article attempts to embed financial technology in the analysis framework of "financial literacy and financial decision-making" and construct reasonable financial literacy indicators based on the survey data of China's Henan and Anhui provinces to explore the impact of financial technology development on the mediating and moderating effects of the development of financial literacy on financial decision-making, thus expanding relevant research on financial literacy.

\section{The Measurement and Mechanism of Financial Literacy}

2.1. Evaluation Methods of Financial Literacy. There are many differences in the measurement of financial literacy in terms of objects, scope, and methods. The object of measurement involves more consumers and young people and less exploration of farmers. The geographic scope of the measurement is mostly limited to provinces and cities and most sample sizes are under 500, which is not universal. However, after the 2008 financial crisis, national surveys began to emerge. Most of the measurement methods adopt single-choice or judgment methods. When scoring financial literacy, use comprehensive total scores or factor analysis to obtain comprehensive factors. When evaluating subjective financial literacy, most use selfevaluation methods, assigning points by five-point scale or seven-point scale. In terms of the specific content of the measurement, most domestic and overseas studies only measure the financial literacy level of residents from compound interest, inflation, and risk diversification $[9,10]$. Some scholars have added several complex dimensions to these three dimensions [11]. On the whole, the existing research is not comprehensive enough to evaluate the level of financial literacy.

\subsection{Development of Financial Literacy and Threshold Model} Research. Noctor et al. first proposed the concept of financial literacy, pointing out that financial literacy is financial skills, including wealth management, financial analysis, and the ability to make full use of financial concepts [12]. Then, Huston formally proposed and defined the conceptual difference between financial literacy and financial knowledge and proposed that financial literacy includes understanding (personal financial knowledge) and application (personal financial application) based on the difference in the US President's Advisory Council on Financial Literacy (PACFL) [13]. The domestic scholar Zhang used Huston's practice to divide financial literacy into two dimensions and evaluated them, using mediating effect and moderating effects to test the impact of residents' subjective and objective financial literacy on financial decision-making. It turns out that objective financial literacy has a positive direct effect on financial decision-making and this effect is also regulated by subjective financial literacy [14].

Wang measured the subjective and objective financial literacy of residents, using self-efficacy theory and behavioral finance theory to study the influence mechanism of financial literacy on financial decision-making in two paths and found that the ability for residents using financial tools to achieve financial decision-making which benefits family is insufficient and the education level, income, and basic grasp of financial knowledge and skills are the main factors that affect household financial decision-making [15]. Tan and Peng used factor analysis to construct a financial capability framework and used Probit model, mediating effect model and instrumental variable method to analyze the relationship between financial capability, financial decision-making, and poverty and found that financial capability can significantly suppress poverty. Financial capacity and poverty present a "U-shaped" relationship and financial ability can alleviate poverty by improving financial decision-making, which has certain practical significance [16]. 
Tong proposed a threshold autoregressive model and later extended this idea to the regression model [17]. Based on the localized research of domestic scholars, this article attempts to introduce the threshold model into the influence path of financial literacy on financial decision-making and analyze it. The contributions of this article are as follows: first of all, through extensive data collection in many counties in Henan and Anhui provinces, to initially understand the status quo of farmers' financial literacy. Secondly, factor analysis is used to objectively empower farmers' financial literacy questionnaires to construct a more accurate index of farmers' financial literacy, which embodies financial decision-making from financial market participation and insurance market participation; then, this paper explores the impact of financial literacy on participation in the two markets and considers the mediating effect of subjective financial literacy when objective financial literacy affects financial decision-making. Finally, taking the popularity of financial technology as the threshold variable and exploring the impact of financial decision-making from the two dimensions of subjective financial literacy and objective financial literacy, and it is concluded that the path of financial literacy on financial decision-making remains unchanged.

2.3. Research Hypothesis. Based on the research by scholars' mentioned above and combined with the threshold effect model, this article proposes the following hypotheses:

$\mathrm{H1}$ : on the basis of controlling other variables, the subjective financial literacy of rural residents has a direct influence on financial decision-making.

$\mathrm{H} 2$ : on the basis of controlling other variables, the objective financial literacy of rural residents has a direct influence on financial decision-making.

$\mathrm{H} 3$ : on the basis of controlling other variables, the objective financial literacy of rural residents has an indirect effect on financial decision-making through subjective financial literacy.

According to social research and actual conditions, individuals' subjective financial literacy tends to be overestimated in self-assessment, resulting in the failure to match the objectively evaluated financial literacy status. At the same time, it is also difficult for residents with a high level of objective financial literacy to make correct judgments about themselves (subjective financial literacy) thus will not use a rational way to invest in financial assets and other investment. This article further proposes the following hypotheses:

H4: on the basis of controlling other variables, the subjective financial literacy of rural residents has a significant moderating effect on the impact of objective financial literacy on financial decision-making.

In addition, studies by scholars have shown that other control variables are also having a certain amount of influence on financial decision-making, including gender, age, education level, health status, marital status, occupational status, and total income in 2017 and 2018. This article sets up the individual characteristics of financial technology exposure as a threshold variable to explore the impact path of rural residents' financial literacy on financial decision-making under the exposure level.

H5: on the basis of controlling other variables and assuming that $\mathrm{H} 1, \mathrm{H} 2, \mathrm{H} 3$, and $\mathrm{H} 4$ are all established, the higher the financial technology penetration, the more the significant impact of financial literacy on financial decision-making.

Based on the abovementioned assumptions and existing research conclusions, this paper constructs a framework diagram of the influence path of rural residents' financial literacy on financial decision-making (Figure 1). It should be noted that subjective financial literacy is the most direct factor that affects household financial decision-making $(\mathrm{H} 1)$, while objective financial literacy can directly affect household financial decision-making (H2); it can also use subjective financial literacy as an intermediary and adjustment channel to affect household financial decision-making (H3 and H4). Among all the influence mechanisms, the popularity of financial technology is expected to play a nonlinear threshold adjustment role (H5).

\section{Data and Model}

3.1. Descriptive Analysis of Data Sources and Samples. This paper uses the data from the "Financial Education for Rural Revitalization-Baseline Investigation of the Jinhui Project in Sichuan, Anhui, and Henan" conducted by the China Financial Education Development Foundation from July to August 2019, which conducted field investigations rural residents in Susong County, Yuexi County, Huoqiu County, Yingshang County, Funan County, Linquan County in Anhui Province and Lankao County, Taikang County, Shenqiu County, Nanzhao County, Tongbai County, Shangcheng County, Henan Province, Xinxian, and other counties. A total of 2,600 questionnaires were distributed, and 2,234 valid questionnaires were returned. Taking the popularity of financial technology as the threshold variable, this paper uses the threshold model to analyze the impact of financial literacy on financial decision-making from the two dimensions of subjective financial literacy and objective financial literacy, using mediating and moderating effects to test the impact of rural residents' subjective and objective financial literacy on the influence path and influence mechanism of their financial decision-making.

Among the 2234 valid samples, the age of the survey subjects is mainly distributed between 40 - and 60 -year olds, accounting for $51 \%$; the number of people aged 60 and over account for $31 \%$ and the number of people under 40 years account for only $18 \%$. The aging phenomenon of the sample is serious. At the same time, the sample shows that the education level of the region is generally low, $33 \%$ of the samples are junior high school education level, $28 \%$ of the samples are elementary school education level, the proportion of illiterate samples is $16 \%$ and the proportion of high school, junior college, and above is only $23 \%$. The 


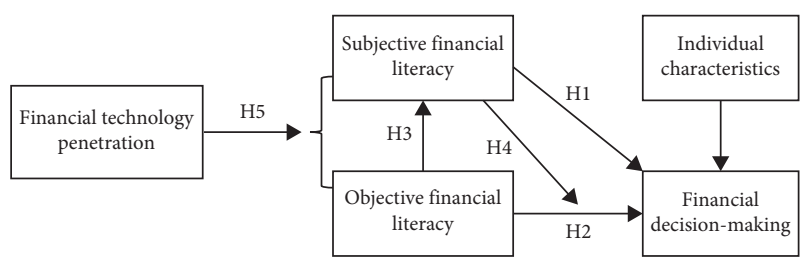

Figure 1: Framework diagram.

overall health status of the survey sample is at the uppermiddle level, 1132 people are in good physical condition, more than $50 \%$, and the overall situation is considered optimistic. However, 642 people are in average physical condition and 460 people are in poor physical condition. Regarding the occupational distribution of the survey sample, the survey sample is mainly engaged in agricultural work, $62 \%$ of them are farming, only 13 people are engaged in the rural e-commerce industry, and 31 people have joined rural enterprises. Entrepreneurship, self-employed, or private enterprises account for $7 \%, 11 \%$ of the survey samples are national staff. It is worth noting that the survey stage is in the mid-year period, so there are only $5 \%$ of the returnees from migrant workers(Table 1).

3.2. Variable Selection and Indicator Construction. This article uses Cronbach's alpha and factor loading values to test the reliability of the survey questionnaire and survey data. Results are within the interval of $99 \%$ confidence level, the Cronbach coefficient value of the subjective financial literacy dimension index reached 0.653 , and the Cronbach coefficient value of the objective financial literacy dimension index was 0.608 , indicating that the objective financial literacy survey part of the questionnaire needs improvement, and the reliability coefficient of the entire survey questionnaire data sheet is close to 0.7 , and the factor loading value of each indicator reaches the upper and lower range of 0.5 , which indicates that the questionnaire has high reliability and the survey sample has passed the internal consistency reliability test.

3.2.1. Evaluating Subjective Financial Literacy. Based on the three indicator evaluation frameworks of the content, process, and background of PISA developed by the Organization for Economic Cooperation and Development (OECD) in 2000 and four dimensions system constructed by China Financial Education Development Foundation: financial awareness, financial knowledge, financial behavior and financial skills, improving, and sublimating on the evaluation framework constructed by Huanhuan Zhang, this article constructs the evaluation system of the subjective financial literacy of Chinese rural residents from 2 aspects and 7 indicators in Table 2. We believe that when measuring the financial literacy of rural residents, the respondent's wrong answer may be due to the long questioning process, carelessness, and failure to hear the question clearly, or the level of understanding is still not enough after exposure to relevant concepts and knowledge. But the answer to "do not know" is mostly because they have never heard of the relevant concept. Therefore, we continue to use Zhichao Yin, Lusardi, and Mitchell's approach to deal with financial capability indicators, distinguishing "do not know" from answering errors and believe that respondents who answered "do not know" lack financial literacy. According to the distribution of the respondents' subjective financial literacy scores at each level, it can be clearly seen that the subjective financial literacy of rural residents is concentrated in the middle-to-lower regions ( 3 to 5 points) $[18,19]$.

3.2.2. Evaluating Objective Financial Literacy. In Table 2, this article constructs an evaluation framework with fivelevel and ten-level indicator through the objective financial literacy of the respondents. For true and false questions and multiple choice questions, the coefficient of variation method is used to score their financial literacy, and the financial literacy scores of rural residents are concentrated in the central region ( $4 \sim 5$ points).

\subsubsection{Conducting Correlation Tests on Subjective and Ob-} jective Financial Literacy and Financial Decision-Making. Table 3 lists the Pearson correlation test results and partial correlation results of subjective and objective financial literacy on financial market participation, insurance market participation, and financial decision-making. Subjective and objective financial literacy has a significant positive correlation with financial market participation and financial decision-making, but the correlation with insurance market participation is negative. While controlling for other variables is unchanged, the overall correlation has dropped significantly. At the same time, the correlation between subjective financial literacy and objective literacy has also decreased to a certain extent, but it is still a significant positive relationship.

3.2.4. Selection of Instrumental Variables. As financial literacy has a certain endogeneity, it can be seen from Arrow's "Learning by Doing" model that people obtain knowledge through learning; technological progress is the product of knowledge and the result of learning. Learning is the continuous summary of experience and experience comes from action. Participation of rural residents in the financial market is also a process of gradual accumulation of learning experience and skills, so there will be a situation in which respondents have accumulated a certain degree of financial literacy in daily life before accepting the interview. According to this situation, this article uses approach of Tan and Peng [16] and selects the subjective evaluation "attention to economic and financial information" as an instrumental variable of financial literacy which can directly affect personal financial literacy but has little relevance to financial decision-making.

3.2.5. Interpreted Variables and Control Variables. In the process of exploring the influence path of rural residents' financial literacy on their financial decision-making, this article regards the residents' financial market participation 
TABLE 1: Basic situation of valid samples.

\begin{tabular}{|c|c|c|c|}
\hline Category & Option & Number of samples & Percentage \\
\hline \multirow{2}{*}{ Gender } & Male & 1439 & 64 \\
\hline & Female & 795 & 36 \\
\hline \multirow{3}{*}{ Age } & Over 60 & 693 & 31 \\
\hline & $40-60$ & 1139 & 51 \\
\hline & Under 40 & 402 & 18 \\
\hline \multirow{4}{*}{ Education level } & High school, junior college, and above & 514 & 23 \\
\hline & Junior high school & 737 & 33 \\
\hline & Primary school & 626 & 28 \\
\hline & Illiterate & 357 & 16 \\
\hline \multirow{3}{*}{ Health conditions } & Good & 1132 & 51 \\
\hline & General & 642 & 29 \\
\hline & Bad & 460 & 20 \\
\hline \multirow{6}{*}{ Occupation } & Farming & 1385 & 62 \\
\hline & Rural e-commerce & 13 & 0.6 \\
\hline & Agribusiness & 31 & 1.4 \\
\hline & Self-employed & 156 & 7 \\
\hline & National staff & 246 & 11 \\
\hline & Migrant workers & 112 & 5 \\
\hline
\end{tabular}

TABLE 2: The evaluation index system of rural residents' financial literacy.

\begin{tabular}{|c|c|c|}
\hline $\begin{array}{l}\text { First level } \\
\text { indicator criteria }\end{array}$ & Second level indicator & Third level indicator \\
\hline \multirow{5}{*}{$\begin{array}{l}\text { Subjective } \\
\text { financial literacy }\end{array}$} & $\begin{array}{l}\text { Financial products self- } \\
\text { awareness }\end{array}$ & $\begin{array}{l}\text { Ability to analyze whether financial products } \\
\text { are legal or not, determining risk and return and } \\
\text { accepting information }\end{array}$ \\
\hline & $\begin{array}{l}\text { Financial knowledge self- } \\
\text { assessment }\end{array}$ & $\begin{array}{c}\text { RMB authenticity recognition, bancassurance } \\
\text { business understanding, policy understanding, } \\
\text { internet payment }\end{array}$ \\
\hline & Basic financial knowledge & $\begin{array}{l}\text { Stock knowledge understanding, financial } \\
\text { knowledge mastery }\end{array}$ \\
\hline & $\begin{array}{l}\text { Understanding and } \\
\text { application of financial } \\
\text { knowledge }\end{array}$ & $\begin{array}{l}\text { Interest rate comparison, compound interest } \\
\text { calculation, insurance limit selection }\end{array}$ \\
\hline & $\begin{array}{l}\text { Awareness of financial } \\
\text { responsibility }\end{array}$ & $\begin{array}{l}\text { Credit responsibility awareness, credit status } \\
\text { disclosure }\end{array}$ \\
\hline
\end{tabular}

Adding the scores of the seven indicators directly

Using the coefficient of variation method to assign weights and score comprehensively

\begin{tabular}{lccc}
\hline $\begin{array}{l}\text { Objective } \\
\text { financial literacy }\end{array}$ & Risk and reward & $\begin{array}{c}\text { Risk and return perception } \\
\text { Asset planning }\end{array}$ & $\begin{array}{c}\text { Choice of saving methods, preference for } \\
\text { investment and financial management }\end{array}$ \\
\hline $\begin{array}{l}\text { Financial } \\
\text { technology } \\
\text { penetration }\end{array}$ & $\begin{array}{c}\text { Financial technology supply } \\
\text { and demand status }\end{array}$ & Supply status & Adding the two levels of scores \\
together
\end{tabular}

and insurance market participation as the two major components of financial decision-making and explores the influence path of financial literacy on dependent variable, financial decision-making. Financial assets defined in this article include bank savings deposits (time deposits and demand deposits), other financial products of banks, insurance, wealth management products of securities and fund companies, gold, futures, and stocks. The variable of rural residents' participation in the financial market is defined as follows: the variable value is assigned as 2 , if rural residents have financial assets other than deposits; the variable value is assigned as 1 , if they have only savings assets; the variable value is assigned as 0 , if they have funds deposited at home and other else. Insurance market participation indicates whether residents hold insurance assets; if they hold, the variable value is assigned as 2, otherwise, assigned as 0 .

The control variables selected in this paper are gender, age, education level, health status, marital status, occupational status, and total income in 2017 and 2018 (Table 4). 
TABLE 3: Pearson correlation test of subjective and objective financial literacy and financial decision-making.

\begin{tabular}{|c|c|c|c|c|c|}
\hline & $\begin{array}{c}\text { Financial market } \\
\text { participation }\end{array}$ & $\begin{array}{l}\text { Insurance market } \\
\text { participation }\end{array}$ & $\begin{array}{c}\text { Financial decision- } \\
\text { making }\end{array}$ & $\begin{array}{l}\text { Subjective financial } \\
\text { literacy }\end{array}$ & $\begin{array}{c}\text { Objective financial } \\
\text { literacy }\end{array}$ \\
\hline \multicolumn{6}{|l|}{ Person correlation } \\
\hline $\begin{array}{l}\text { Subjective financial } \\
\text { literacy }\end{array}$ & $0.4794^{* *}$ & -0.0268 & $0.4566^{* *}$ & 1.0000 & $0.4997^{* *}$ \\
\hline $\begin{array}{l}\text { Objective financial } \\
\text { literacy }\end{array}$ & $0.4455^{* *}$ & $-0.0470^{* * *}$ & $0.4181^{* *}$ & $0.4997^{* *}$ & 1.0000 \\
\hline \multicolumn{6}{|l|}{ Partial correlation test } \\
\hline $\begin{array}{l}\text { Subjective financial } \\
\text { literacy }\end{array}$ & 0.3333 & $-0.0042^{* * *}$ & $0.3183^{* * *}$ & 1.0000 & $0.3848^{* * *}$ \\
\hline $\begin{array}{l}\text { Objective financial } \\
\text { literacy }\end{array}$ & $0.2646^{* * *}$ & $-0.0381^{* * *}$ & 0.2369 & $0.3848^{* * *}$ & 1.0000 \\
\hline
\end{tabular}

Note: ${ }^{* * *}$ The significance level is $1 \% .{ }^{* *}$ The significance level is $5 \%$.

TABLE 4: Variable overview and assignment status, basic statistics, and coefficient symbol.

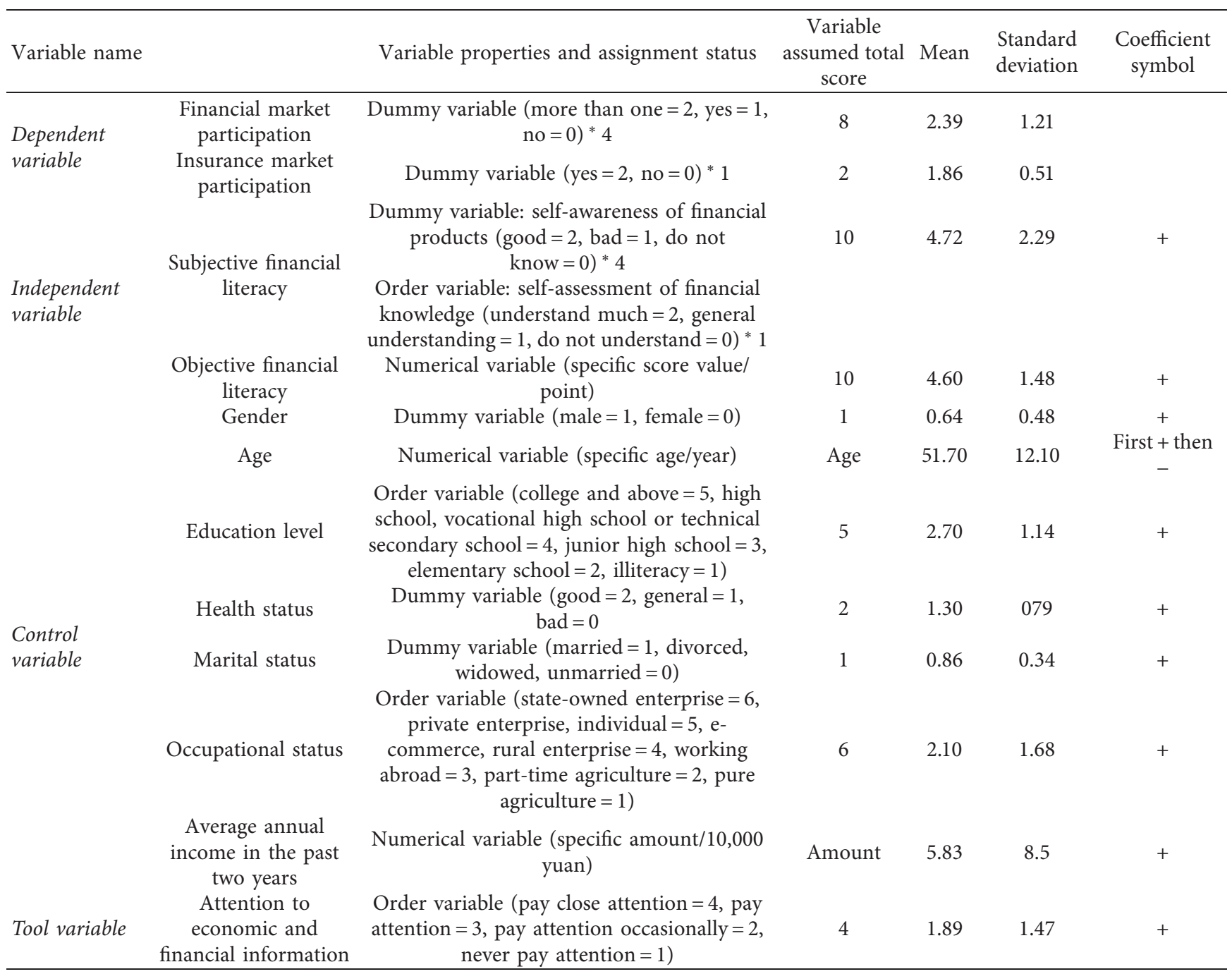

3.3. Model Selection. Based on the above research hypotheses, this article needs to construct direct effect model, mediating effect, moderating effect model, and threshold regression model between variables. Given that both financial market participation and insurance market participation are dummy variables, while subjective and objective financial literacy are ordered variables, this paper uses the Probit model to analyze the impact of rural residents' financial literacy on financial market participation and insurance market participation and use a multiple choice model to analyze the impact of rural 
residents' objective financial literacy on subjective financial literacy and the impact of financial literacy on financial decision-making under different levels of financial technology penetration. The model of this article is as follows:

(1) The mediating effect model of financial market participation or insurance market participation:

$$
\begin{aligned}
\mathrm{SFL} & =\alpha_{11}+\mathrm{OFL}+\beta X+\mu, \\
Y & =1\left(\alpha_{21} \mathrm{OFL}+\beta X+\mu>0\right), \\
Y & =1\left(\alpha_{31} \mathrm{OFL}+\alpha_{32} \mathrm{SFL}+\beta X+\mu\right) .
\end{aligned}
$$

In formulas (1)-(3), SFL is the subjective financial literacy, OFL is the objective financial literacy, $X$ is the controlled variable, $Y$ are the financial market participation (finance) and insurance market participation (insurance), where, $Y=1$ represents financial market participation or insurance market participation and $Y=0$ means no participation.

(2) The moderating effect model of financial market participation or insurance market participation:

$Y=1\left(\alpha_{41} \mathrm{OFL}+\alpha_{42} \mathrm{SFL}+\alpha_{43} \mathrm{OFL} \times \mathrm{SFL}+\beta X+\mu>0\right)$.

In (4), OFL $\times$ SFL is the cross-product of subjective financial literacy and objective financial literacy.

(3) Threshold regression models of rural residents' financial literacy on financial decision-making under different financial technology popularity:

$$
\begin{aligned}
Y= & \alpha_{51} \mathrm{OFL}+\alpha_{52} \mathrm{SFL}+\alpha_{53} Z \\
& +\beta X+\mu, \quad 0<Z<d_{1}, \\
Y= & \alpha_{61} \mathrm{OFL}+\alpha_{62} \mathrm{SFL}+\alpha_{63} Z \\
& +\beta X+\mu, \quad d_{1}<Z<d_{2}, \\
Y= & \alpha_{71} \mathrm{OFL}+\alpha_{72} \mathrm{SFL}+\alpha_{73} Z \\
& +\beta X+\mu, \quad Z>d_{2} .
\end{aligned}
$$

In formulas (5)-(7), $Z$ is called the threshold variable, and $d_{1}, d_{2}$ are called the threshold values.

\section{Empirical Test Results}

In this paper, when testing the financial literacy of rural residents on financial decision-making under different levels of financial technology penetration, first, the permutation regression method is used to search, and after the threshold value is determined, the Bootstrap method is used to simulate LM tests, the asymptotic distribution of the F statistic, and its critical value to determine whether there is a threshold effect. Finally, the two optimal threshold values for this threshold regression are determined by 1 and 3 after repeated inspections for many times.
Then, by establishing regression models of subjective financial literacy and objective financial literacy on financial market participation and insurance market participation in two types of financial decision-making, this article tests whether subjective and objective financial literacy has a direct impact on financial decision-making and uses hierarchical regression analysis to test the mediating effect of subjective financial literacy in the impact of objective financial literacy on these two types of financial decisionmaking. In order to ensure that the hierarchical regression analysis method can produce a higher statistical effect, this paper uses the coefficient product test method (Sobel test) to determine the mediating effect. In order to maximize excluding the impact of possible endogenous problems in financial literacy, this article uses "attention to economic and financial information" as an instrumental variable of financial literacy, carries out two-stage estimation and GMM estimation, and uses Hausman's test method to test the model. Finally, in certain three-stage financial technology penetration and threshold regression model, the significance of the financial literacy on financial decisionmaking is tested.

\subsection{Path Test of the Influence of Rural Residents' Financial} Literacy on Financial Market Participation. In order to comprehensively explore the influence mechanism of rural residents' financial literacy in participating in the financial market, this paper conducts related tests on the direct impact of rural residents' subjective financial literacy and objective financial literacy on financial decision-making, as well as the intermediary and regulatory effects. In the process of regression, the heteroscedastic White test was used to test all models, and it was found that the probability value of Obs $* R$-squared in all models was far less than the significance level of 0.05 , the null hypothesis was rejected, and heteroscedasticity existed. The weighted least squares method (WLS) is used to correct the heteroscedasticity and the forward search method in the automatic stepwise regression method which is used to perform regression secondary test on the revised model in order to eliminate multicollinearity problems in the model. The regression results obtained are shown in Table 5.

Model M1 tests whether there is a significant direct effect of subjective financial literacy on financial decision-making. The regression results show that the coefficient value of subjective financial literacy is 0.212 , indicating that under the control of other conditions unchanged, the higher level the subjective financial literacy rural residents have, the more they tend to participate in the financial market. Hypothesis $\mathrm{H} 1$ is confirmed.

Model M2 tests whether objective financial literacy has a significant direct effect on financial decision-making. The regression results show that the coefficient value of objective financial literacy is 0.290 , indicating that under the control of other conditions unchanged, the higher the objective financial literacy of rural residents, the more inclined to participate in the financial market. Hypothesis $\mathrm{H} 2$ is confirmed. 
TABLE 5: Regression results of rural residents' financial literacy on financial market participation models.

\begin{tabular}{|c|c|c|c|c|c|}
\hline & Model M1 & Model M2 & Model M3 & Model M4 & Model M5 \\
\hline $\begin{array}{l}\text { Variable } \\
\text { Subjective financial }\end{array}$ & $\begin{array}{c}\text { Financial market } \\
\text { participation } \\
* * *\end{array}$ & $\begin{array}{c}\text { Financial market } \\
\text { participation }\end{array}$ & $\begin{array}{c}\text { Subjective } \\
\text { financial literacy }\end{array}$ & $\begin{array}{c}\text { Financial market } \\
\text { participation } \\
* * *\end{array}$ & $\begin{array}{c}\text { Financial market } \\
\text { participation } \\
* * *\end{array}$ \\
\hline literacy & $(15.81)$ & & & $(11.42)$ & $(3.23)$ \\
\hline $\begin{array}{l}\text { Objective financial } \\
\text { literacy }\end{array}$ & & $* * *$ & $* * *$ & $* * *$ & $* * *$ \\
\hline & & $(15.04)$ & $(18.52)$ & $(9.86)$ & $(3.84)$ \\
\hline \multicolumn{6}{|l|}{$\begin{array}{l}\text { Cross-term of subjective } \\
\text { and objective }\end{array}$} \\
\hline Gender & & & $* * *$ & & $(1.51)$ \\
\hline & $(-0.56)$ & $(-1.62)$ & $(-4.54)$ & $(-0.61)$ & $(-0.62)$ \\
\hline Age & $* * *$ & $* *$ & $* * *$ & $* * *$ & $* * *$ \\
\hline & $(-3.65)$ & $(-2.22)$ & $(4.20)$ & $(-3.24)$ & $(-3.19)$ \\
\hline $\mathrm{Age}^{2}$ & $* *$ & & $* *$ & $* *$ & $* *$ \\
\hline & $(2.43)$ & $(0.92)$ & $(-5.30)$ & $(2.17)$ & $(2.11)$ \\
\hline Education level & $* * *$ & $* * *$ & $* * *$ & $* * *$ & $* * *$ \\
\hline & $(7.11)$ & $(7.59)$ & $(7.66)$ & $(5.95)$ & $(5.83)$ \\
\hline Health status & $* *$ & & $* * *$ & $* *$ & $* *$ \\
\hline & $(-2.16)$ & $(-0.99)$ & $(4.04)$ & $(-2.10)$ & $(-2.12)$ \\
\hline Marital status & $(-1.07)$ & $(-1.14)$ & $(-0.03)$ & $(-1.15)$ & $(-1.11)$ \\
\hline Occupations & $* * *$ & $* *$ & & $* *$ & $* *$ \\
\hline & $(2.91)$ & $(2.55)$ & $(1.37)$ & $(2.35)$ & $(2.29)$ \\
\hline Average annual income & $* * *$ & $* * *$ & $* * *$ & $* * *$ & $* * *$ \\
\hline & $(4.24)$ & $(5.48)$ & $(5.52)$ & $(4.28)$ & $(4.20)$ \\
\hline _cons & $* * *$ & $* * *$ & & $* * *$ & $* * *$ \\
\hline $\bar{P}$ value ( $F$ test $)$ & $(7.57)$ & $(5.19)$ & $(-0.85)$ & $(5.57)$ & $(5.77)$ \\
\hline $\begin{array}{l}\text { Endogenous test, } P \text { value } \\
\left(\chi^{2} \text { statistics }\right)\end{array}$ & 0.00001 & 0.00001 & 0.00001 & 0.00001 & 0.00001 \\
\hline & 0.56 & 0.87 & & & \\
\hline$N$ & 2229 & 2232 & 2229 & 2229 & 2229 \\
\hline $\mathrm{R} 2$ & 0.313 & 0.304 & 0.374 & 0.342 & 0.342 \\
\hline r2_a & 0.31 & 0.30 & 0.37 & 0.34 & 0.34 \\
\hline
\end{tabular}

Note: ${ }^{* * *}$ The significance level is $1 \% .{ }^{* *}$ The significance level is $5 \% .{ }^{*}$ The significance level is $10 \%$.

Since the models have heteroscedasticity, GMM iterative estimation is performed on models M1 and M2 and the final Hausman test results show that models M1 and M2 cannot reject the null hypothesis with the probability of $P=0.56$ and $P=0.87$, respectively, indicating that subjective financial literacy and objective financial literacy are both exogenous explanatory variables in the model.

In the test of the mediating effect, three regressions are required: first, carry out the return of objective financial literacy to financial market participation (model M2). The results show that objective financial literacy variables are significant, which is the prerequisite for the existence of the mediating effect of the main body effect. Second, carry out the regression of objective financial literacy to subjective financial literacy (model M3). The results show that objective financial literacy variables are significant, indicating that objective financial literacy has a significant impact on subjective financial literacy. Finally, carry out subjective and objective financial literacy to the return of financial market participation (model M4). The result shows that both subjective financial literacy and objective financial literacy variables are significant. The $Z$ value obtained by the Sobel test is -1.63 which rejects the null hypothesis without mediating the effect at the $5 \%$ significance level. The conclusion is that subjective financial literacy plays a certain degree of mediating effect in the influence of objective financial literacy on financial decision-making and the mediating effect accounts for 26.7\%. Hypothesis H3 is confirmed.

When testing the moderating effect, the intersection of subjective financial literacy and objective financial literacy is used to evaluate its significance. Model M5 (subjective financial literacy, objective financial literacy, subjective financial literacy, and objective financial literacy return to financial market participation) is built and the results obtained show that subjective and objective financial literacy and their cross-terms all play a positive role in promoting financial market participation and the cross-term of subjective financial literacy and objective financial literacy has more significant positive effect on the regression coefficient value of objective financial literacy relative to subjective financial literacy. It appears that the impact of objective financial literacy on financial decision-making is regulated by subjective financial literacy and hypothesis $\mathrm{H} 4$ is confirmed. From the empirical results, due to the existence of the positive promotion effect of the subjective and objective financial literacy cross-term, rural residents with higher subjective financial literacy will promote their participation 
in the financial market with the improvement of their objective financial literacy level.

Rural residents of different ages have an " $\mathrm{M}$ distribution" in participation in the financial market (the two peaks are 23 and 48 years old, respectively). Obviously, the results show that the higher the level of education, the higher the average annual income, and the better the health of the respondents, the higher their interest in financial market participation. There is no significant amount of statistical data indicating that married people are more inclined to participate in the financial market than other unmarried and divorced groups. At the same time, rural residents engaged in nonagriculture are more willing to participate in the financial market.

\subsection{Test of the Influence Path of Rural Residents' Financial} Literacy on Insurance Market Participation. With the increasing activity of the rural insurance market, more and more farmers have the awareness of avoiding risks and reducing losses caused by risks. Therefore, exploring such an active market is particularly necessary for the exploration of financial decision-making. First, carry out relevant tests on the direct influence of rural residents' subjective financial literacy and objective financial literacy on financial decisionmaking and the mediating effect and moderating effect and perform heteroscedasticity tests on all models. It is found that there is heteroscedasticity and the FGLS method is used to modify. All models use the forward search method in the automatic stepwise regression method to perform regression to eliminate the multicollinearity in the model. The model test results are shown in Table 6.

Model M1 tests whether subjective financial literacy has a direct effect on insurance market participation. The regression results show that the coefficient of subjective financial literacy is negative, which is completely opposite to the direction of financial literacy participation. Hypothesis $\mathrm{H} 1$ is confirmed. Model M2 tests whether objective financial literacy has a direct effect on insurance market participation. The regression results show that the objective financial literacy coefficient is negative, which means that when the respondent has higher objective financial literacy, the less likely it is to participate in the insurance market. This is different from what we usually understand. It is not surprising that financial literacy and insurance market participation show a negative relationship. Firstly, the terms of Chinese insurance products are full of professional terms, which are difficult for ordinary people to understand, and insurance intermediaries in rural areas are very underdeveloped, causing residents with higher financial literacy to show greater resistance to insurance products; secondly, in recent years, a substitute for commercial insurance, social insurance, has been continuously improved, making commercial insurance products less attractive to residents with high financial literacy; thirdly, because the designed questionnaire puts insurance and bank products alongside each other, the interviewees may mistakenly believe that the insurance products in the questionnaire refer to wealth management products, thereby exacerbating this negative relationship.
In the same way, the Hausman test is provided to learn that the Models M1 and M2 cannot reject the null hypothesis with the probability of $P=0.23$ and $P=0.19$, respectively, which indicates that subjective financial literacy and objective financial literacy are both exogenous explanatory variables in the model.

In the test of the mediating effect, three regressions are required: first, the regression of objective financial literacy to insurance market participation (Model M2). The results show that objective financial literacy variables are significant, which is the premise for the existence of the mediating effect of the main body effect. Second, the regression of objective financial literacy to subjective financial literacy (Model M3). The results show that objective financial literacy variables are significant, indicating that objective financial literacy has a significant impact on subjective financial literacy. Finally, the regression of subjective financial literacy and objective financial literacy on financial market participation (Model M4). The result shows that the subjective financial literacy and objective financial literacy variables are both significant. The $Z$ value obtained by the Sobel test is -2.43 and the null hypothesis is rejected without mediating effect at the $5 \%$ significance level. It is concluded that subjective financial literacy plays a certain degree of mediating effect in the influence of objective financial literacy on financial decision-making and the mediating effect accounts for $12.07 \%$. Hypothesis H3 is confirmed.

When testing the moderating effect, the intersection of subjective financial literacy and objective financial literacy is used to evaluate its significance. The results obtained from Model M5 (subjective financial literacy, objective financial literacy, subjective financial literacy, and objective financial literacy return to financial market participation) show that subjective and objective financial literacy plays a positive role in promoting insurance market participation, but the crossterm of subjective financial literacy and objective financial literacy has a weaker reverse effect on the regression coefficient value of objective financial literacy than subjective financial literacy. It can be seen that the impact of objective financial literacy on financial decision-making is regulated by subjective financial literacy and hypothesis $\mathrm{H} 4$ is confirmed. From the empirical results, due to the existence of the reverse hindrance effect of the subjective and objective financial literacy cross-term, for rural residents with higher subjective financial literacy, improving their objective financial literacy level will not necessarily promote their participation in the insurance market. It may play a blocking role.

The higher the average annual income, the higher the interest of the surveyed persons engaged in nonagricultural occupations in participating in the insurance market. There is no significant amount of statistical data indicating that married persons are more inclined to participate in the insurance market than other unmarried, divorced, and other groups, which means married people have poor insurance awareness. At the same time, the lower the education level and the lower the age, they are more inclined to participate in the insurance market. 
TABLE 6: Regression results of rural residents' financial literacy on insurance market participation models.

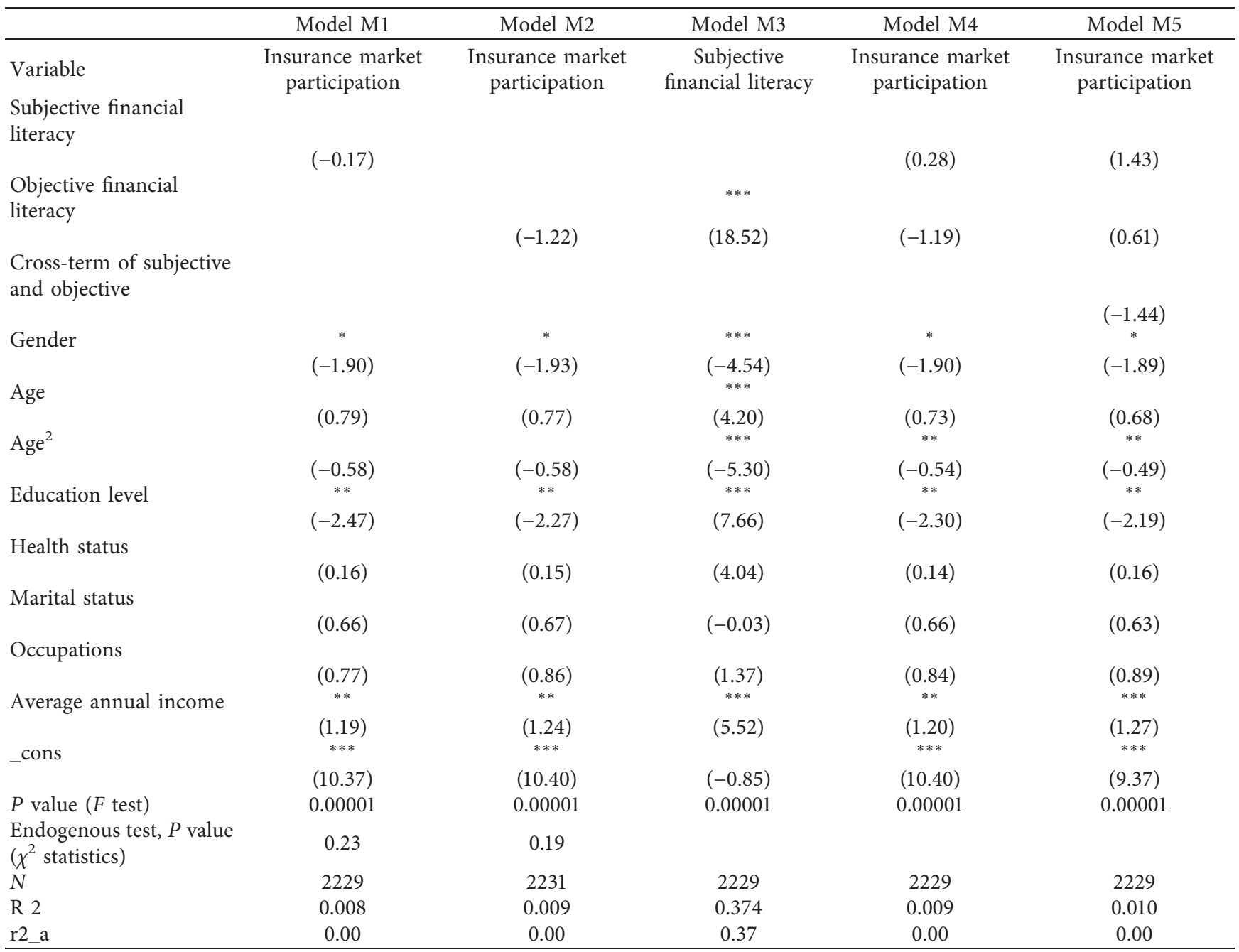

Note: ${ }^{* * *}$ The significance level is $1 \% .{ }^{* *}$ The significance level is $5 \% .{ }^{*}$ The significance level is $10 \%$.

\subsection{Test of the Effect of Rural Residents' Financial Literacy on Financial Decision-Making under Different Financial Technology Popularization}

4.3.1. Model interpretation. Based on the threshold autoregression model (TAR) proposed by Tong [17] and draws on the idea of the endogenous panel threshold regression model proposed by Hansen [20], this paper first expresses the single threshold regression model without partition as follows:

$$
\begin{aligned}
Y= & \left\{\alpha_{51} \mathrm{OFL}+\alpha_{52} \mathrm{SFL}+\alpha_{53} Z+\beta X+\mu\right\}(d \leq Z) \\
& +\left\{\alpha_{61} \mathrm{OFL}+\alpha_{62} \mathrm{SFL}+\alpha_{63} Z+\beta X+\mu\right\}(d>Z)+\varepsilon .
\end{aligned}
$$

Among them, $\varepsilon$ are the residual items and the coefficients $\alpha_{51}, \alpha_{52}, \alpha_{61}, \alpha_{62}, Z$ are parameters to be estimated.

Carrying out least square estimation on regression model (8) and obtaining the residual sum of squares can obtain the threshold estimated value $Z$. Since the obtained threshold is proposed on the null hypothesis of no threshold effect, it needs to be confirmed whether there is a threshold effect in the model. The null hypothesis and alternative hypothesis tested are

$$
\begin{aligned}
& \text { H0: } \alpha_{51}=\alpha_{61}, \\
& \text { H1: } \alpha_{52} \neq \alpha_{62} .
\end{aligned}
$$

Let $\mathrm{S} 0$ be the sum of squares of the residual items under the null hypothesis (no threshold effect), and S1 is the residual sum of squares under the condition of threshold effect. The F statistic of the corresponding Lagrange multiplier test can be easily obtained:

When $F<$ the corresponding critical value under the given significance level, the null hypothesis is not rejected, indicating that the model does not have a threshold effect;

When $F>$ the critical value corresponding to the given significance level, the null hypothesis is rejected, indicating that the model has a threshold effect, and under different mechanisms, the coefficient values of $\alpha_{51}, \alpha_{52}, \alpha_{61}, \alpha_{62}$ are different.

Whether the second threshold exists and its estimation method and test method are the same as the first threshold are judged. 
TABLE 7: Parameter estimates of double thresholds for financial technology penetration.

\begin{tabular}{llll}
\hline Variable & Coefficient & Standard error & $t$ value \\
\hline$Z<1-1210$ obs & & & \\
Financial decision-making & 0.0000 & 0.0137 & 0.0000 \\
Subjective financial literacy & 0.0000 & 0.0124 & 0.0000 \\
Objective financial literacy & 0.0000 & 0.0084 & 0.0000 \\
$1 \leq Z<3-506$ obs & & & \\
Financial decision-making & 0.1400 & 0.0175 & 7.9824 \\
Subjective financial literacy & 0.0126 & 0.0128 & 0.9851 \\
Objective financial literacy & 0.0655 & 0.0156 & 4.1855 \\
$3 \leq Z-514$ obs & & & \\
Financial decision-making & 0.2487 & 0.01421 & 7.5607 \\
Subjective financial literacy & 0.19141 & 0.0118 & 6.2230 \\
Objective financial literacy & 0.2649 & 0.01491 & 7.7320 \\
\hline
\end{tabular}

4.3.2. Empirical Analysis. The confidence interval constructed by the measurement software and the number of corresponding interval values are clearly pointed out that 1 and 3 are the two threshold values under the threshold effect model and the threshold regression parameter values obtained are shown in Table 7.

From the estimated results, it can be seen that under different levels of Fintech penetration, the financial literacy of rural residents has different elasticities of influence on financial decision-making, and with the expansion of Fintech contact, the elasticity of influence is gradually increasing, which shows that Fintech penetration has nonlinear structural characteristics of influence on subjective financial literacy and objective financial literacy. When Fintech penetration is less than 1 , the coefficient value is 0 . However, this does not mean that when financial technology is not fully popularized in rural areas, Fintech penetration has no effect on farmers' financial literacy and financial decision-making. It is just not relevant from a statistical point of view. But from the reality, without the popularization of financial technology, farmers' financial literacy is likely to have a negative and significant impact in making financial decisions. When Fintech penetration is between 1 and 3 , the coefficients of financial decision-making and subjective and objective financial literacy are all positive and the increase in objective financial literacy is the most obvious. Through direct influence and the adjustment effect of subjective financial literacy, the coefficient of financial decision-making finally reaches $14 \%$. As a relatively exogenous variable, Fintech penetration has played a good role in enhancing the influence of rural residents' financial literacy on their financial decision-making. When Fintech penetration reaches a relatively high level, the intermediary adjustment effect of subjective financial literacy is more significant. At this time, the affected variable (financial decision-making) is not only directly affected by subjective and objective financial literacy but also by the effective use of intermediary models and cross-terms, allowing rural residents' financial decision-making to reach a relative peak value. So far, hypothesis H5 is verified.

\section{Conclusion and Inspiration}

Subjective financial literacy and objective financial literacy have a significant positive impact on financial market participation but have a negative direct effect in insurance market participation. Subjective financial literacy plays an incomplete intermediary role in the impact of the objective financial literacy on financial market participation and insurance market participation and the mediating effects account for $26.7 \%$ and $12.07 \%$. Objective financial literacy is regulated by subjective financial literacy in financial market participation and insurance market participation. The higher the degree of financial technology penetration, the financial literacy of rural residents will have a more significant impact on their financial decision-making under the mediating and regulatory effects.

The financial market participation of respondents of different ages shows an "M-shaped" distribution (the peek is around 23 and 48). Married people have weak financial participation capabilities and poor insurance awareness, thus making it more difficult for them to participate in the financial market and the insurance market. The higher the education level of individuals, the higher the possibility of participating in the financial market and the more optimistic about participating in the financial market, but the lower the probability of participating in the insurance market. The higher the degree of nonagricultural occupation, respondents are more likely to participate in the financial market and insurance market. The higher the average annual household income, the higher the possibility of participating in the financial market will be. The better their health is, the greater their enthusiasm for participating in the financial market.

Promoting the popularization of financial technology in rural areas has profound significance for rural revitalization. A series of chain reactions driven by financial technology include the improvement of financial services, financial education, and financial literacy. Each country or region has different policies and measures to improve residents' financial literacy; however, their focus is on the improvement of objective financial literacy and ignores the impact of subjective financial literacy on residents' financial decision-making. Our research shows that the financial decisions made by rural residents are not only directly influenced by subjective and objective financial literacy but also influenced by objective financial literacy on financial decision-making and subjective financial literacy has mediating effect. When financial technology penetration is introduced as a threshold variable, this path of influence remains unchanged. Therefore, while paying attention to the improvement of residents' objective financial literacy, national policy makers and implementers should also give equal attention to subjective financial literacy. Financial institutions can also rely on financial technology to pay attention to residents' subjective demands and design-personalized financial products. When promoting financial technology penetration in rural areas, 
we should also pay attention to individual characteristics such as age level, income status, health status, marital status, occupation type, education level, and financial education. In this way, the effect of the policy implementation will be better and financial institutions will pay more attention to the characteristics of differentiation. Financial technology penetration, financial literacy, and financial decision-making will also form a good circular and mutually beneficial effect.

At the same time, the conclusions of this article show that a financial literacy improvement plan should be formulated to strengthen the popularization of financial education in rural areas, encourage farmers to participate in the financial market, and improve individual financial wellbeing through asset allocation. The focus is on the middleaged and young people in rural areas. As a vital part of improving financial literacy, adolescents are the main group to achieve poverty reduction in rural areas in the future. Improving their financial literacy is conducive to the formation of a chain effect and the realization of sustainable poverty reduction, allowing farmers to experience the benefits of asset allocation through actual financial operations, so as to break the shackles of rural residents' traditional ideas of small farmers and establish models, thus achieving the autonomous driving effect of village residents, rather than relying solely on the government's up-to-down propaganda.

\section{Data Availability}

The data used to support the findings of this study were supplied by China Foundation for Development of Financial Education under license and so cannot be made freely available. Requests for access to these data should be made to China Foundation for Development of Financial Education.

\section{Conflicts of Interest}

The authors declare that they have no conflicts of interest regarding the publication of this paper.

\section{Acknowledgments}

This work was supported by the National Natural Science Foundation of China (grant no. 72003059). The authors would like to thank China Foundation for Development of Financial Education for funding this research.

\section{References}

[1] A. Lusardi and O. S. Mitchell, "Baby boomer retirement security: the roles of planning, financial literacy, and housing wealth," Journal of Monetary Economics, vol. 54, no. 1, pp. 205-224, 2007.

[2] D. Moore, "Survey of financial literacy in Washington state: knowledge, behavior, attitudes, and experiences," Technical Report No. 03-39, Social and Economic Sciences Research Center, Washington State University, Pullman, WA, USA, 2003.

[3] Organisation for Economic Co-Operation and Development (OECD), OECD/INFE Toolkit for Measuring Financial
Literacy and Financial Inclusion, OECD Publishing, Paris, France, 2015.

[4] J. J. Xiao, C. Chen, and F. Chen, "Consumer financial capability and financial satisfaction," Social Indicators Research, vol. 118, no. 1, pp. 415-432, 2013.

[5] T. Dohmen, A. Falk, D. Huffman, and U. Sunde, "Are risk aversion and impatience related to cognitive ability?" American Economic Review, vol. 100, no. 3, pp. 1238-1260, 2010.

[6] M. Rooij, A. Lusardi, and R. Alessie, "Financial literacy and stock market participation," Journal of Financial Economics, vol. 101, no. 2, pp. 449-472, 2011.

[7] C. A. Robb, "Financial knowledge and credit card behavior of college students," Journal of Family and Economic Issues, vol. 32, no. 4, pp. 690-698, 2011.

[8] H. Zhang and X. Xiong, "The influence path and empirical test of rural residents' financial literacy on financial decisionmaking-based on the survey of Shandong province," Journal of Huazhong Agricultural University (Social Sciences Edition), vol. 2018, no. 6, pp. 75-85, 2018.

[9] A. Lusardi, O. S. Mitchell, and Mitchell, "Financial literacy and retirement planning in the United States," Journal of Pension Economics and Finance, vol. 10, no. 4, pp. 509-525, 2011.

[10] A. Lusardi and P. Tufano, "Debt literacy, financial experiences, and overindebtedness," Journal of Pension Economics and Finance, vol. 14, no. 4, pp. 332-368, 2015.

[11] A. Lusardi and O. S. Mitchell, "Financial literacy around the world: an overview," Journal of Pension Economics and Finance, vol. 10, no. 4, pp. 497-508, 2011.

[12] M. Noctor, S. Stoney, and R. Strading, "Financial literacy: a discussion of concepts and competences of financial literacy and opportunities for its introduction into young peopled leaming," Report Prepared for the National Westminster Bank, National Foundation for Education Research, London, UK, 1992.

[13] S. J. Huston, "Measuring financial literacy," Journal of Consumer Affairs, vol. 44, no. 2, pp. 296-316, 2010.

[14] H. Zhang, "Research on rural residents' financial literacy evaluation and influencing factors-based on survey data from Hubei and Henan provinces," China Rural Survey, vol. 2017, no. 3, pp. 131-144, 2017.

[15] H. Wang, Research on the Influence of Urban Residents' Financial Literacy on Family Financial Decision, Northwest Normal University, Lanzhou, China, 2018.

[16] Y. Tan and Q. Peng, "Financial capacity, financial decisionmaking and poverty," Economic Theory and Business Management, vol. 2019, no. 2, pp. 62-77, 2019.

[17] H. Tong, On a Threshold Model, Sijthoff \& Noordhoff, Alphen aan den Rijn, The Netherlands., 1978.

[18] Z. Yin, Q. Song, and Y. Wu, "Financial knowledge, investment experience and family asset selection," Economic Research Journal, vol. 49, no. 4, pp. 62-75, 2014.

[19] A. Lusardi and O. S. Mitchell, "Financial literacy and retirement preparedness: evidence and implications for financial education programs," Business Economics Volume, vol. 42, pp. 35-44, 2007.

[20] B. E. Hansen, "Sample splitting and threshold estimation," Econometrica, vol. 68, no. 3, pp. 575-603, 2000. 